\title{
Duplex TaqMan Hydrolysis Probe-Based Molecular Assay for Simultaneous Detection and Differentiation of Burkholderia pseudomallei and Leptospira spp. DNA
}

\author{
Mohammad Ridhuan Mohd Ali $\left(\mathbb{D},{ }^{1,2}\right.$ Lee Lih Huey, ${ }^{2}$ Phiaw Chong Foo $\left(\mathbb{D},{ }^{3,4}\right.$ \\ Yuan Xin Goay (D), ${ }^{5,6}$ Asmaliza S. Ismail, ${ }^{7}$ Khairul Mohd Fadzli Mustaffa, ${ }^{6}$ Ismail Aziah, ${ }^{6}$ \\ Phua Kia Kien $\left(\mathbb{D},{ }^{6}\right.$ Azian Harun ${ }^{(D)},{ }^{2,8}$ Nabilah Ismail $\mathbb{D}^{2,8}$ and Chan Yean Yean $(\mathbb{D})^{2,8}$ \\ ${ }^{1}$ Bacteriology Unit, Infectious Disease Research Centre, Institute for Medical Research, Ministry of Health Malaysia, \\ National Institutes of Health Complex, Bandar Setia Alam, 40170 Shah Alam, Selangor, Malaysia \\ ${ }^{2}$ Department of Medical Microbiology \& Parasitology, School of Medical Sciences, Universiti Sains Malaysia, Health Campus, \\ 16150 Kubang Kerian, Kelantan, Malaysia \\ ${ }^{3}$ Acarology Unit, Infectious Disease Research Centre, Institute for Medical Research, Ministry of Health Malaysia, \\ National Institutes of Health Complex, Bandar Setia Alam, 40170 Shah Alam, Selangor, Malaysia \\ ${ }^{4}$ School of Health Sciences, Universiti Sains Malaysia, Health Campus, 16150 Kubang Kerian, Kelantan, Malaysia \\ ${ }^{5}$ INTI International College Penang, Lebuh Bukit Jambul, Bukit Jambul, 11900 Bayan Lepas, Pulau Pinang, Malaysia \\ ${ }^{6}$ Institute for Research in Molecular Medicine, Universiti Sains Malaysia, Health Campus, 16150 Kubang Kerian, Kelantan, Malaysia \\ ${ }^{7}$ Research Policy \& Planning Division, National Institutes of Health, Ministry of Health Malaysia, Bandar Setia Alam, \\ 40170 Shah Alam, Selangor, Malaysia \\ ${ }^{8}$ Hospital Universiti Sains Malaysia, Health Campus, 16150 Kubang Kerian, Kelantan, Malaysia
}

Correspondence should be addressed to Mohammad Ridhuan Mohd Ali; ridhuanali@gmail.com and Chan Yean Yean; yeancyn@yahoo.com

Received 25 February 2019; Revised 29 May 2019; Accepted 30 May 2019; Published 2 July 2019

Academic Editor: Francesca Mancianti

Copyright (C) 2019 Mohammad Ridhuan Mohd Ali et al. This is an open access article distributed under the Creative Commons Attribution License, which permits unrestricted use, distribution, and reproduction in any medium, provided the original work is properly cited.

\begin{abstract}
Melioidosis and leptospirosis, caused by two different bacteria, Burkholderia pseudomallei and Leptospira spp., are potentially fatal infections that share a very similar spectrum of clinical features and cause significant mortality and morbidity in humans and livestock. Early detection is important for better clinical consequences. To our knowledge, there is no diagnostic tool available to simultaneously detect and differentiate melioidosis and leptospirosis in humans and animals. In this study, we described a duplex TaqMan probe-based qPCR for the detection of B. pseudomallei and Leptospira spp. DNA. The performance of the assay was evaluated on $20 \mathrm{~B}$. pseudomallei isolates, 23 Leptospira strains, and 39 other microorganisms, as well as two sets of serially diluted reference strains. The duplex qPCR assay was able to detect $0.02 \mathrm{pg}$ ( 4 copies) Leptospira spp. DNA and $0.2 \mathrm{pg}$ ( 25.6 copies) B. pseudomallei DNA. No undesired amplification was observed in other microorganisms. In conclusion, the duplex qPCR assay was sensitive and specific for the detection of B. pseudomallei \& Leptospira spp. DNA and is suitable for further analytical and clinical evaluation.
\end{abstract}

\section{Introduction}

Burkholderia pseudomallei and Leptospira are two important infectious agents for melioidosis and leptospirosis, respectively [1-3]. The Gram-negative B. pseudomallei is recognized as CDC Tier 1 select agent and a Category
B Priority Pathogen by the National Institute of Allergy and Infectious Diseases (NIAID), in addition to leptospirosis, which has been added to the Emerging Infectious Diseases category (https://www.niaid.nih.gov/research/ emerging-infectious-diseases-pathogens). Both organisms are normally found in the soil and freshwater environment $[4,5]$. 
In addition to their ubiquitous habitats, these organisms routinely infect animals, such as cattle, sheep, and horses. Certain animal classes such as rats may asymptomatically carry Leptospira. It is generally accepted that animals are responsible for shedding and maintenance of Leptospira and B. pseudomallei in the environments, through their urines and faeces [5-7]. Human cases are usually associated with interactions with the contaminated environments $[6,8]$. To date, increasing cases of melioidosis and leptospirosis have been reported worldwide, especially in the tropical and subtropical regions $[1,6]$.

Infections by $B$. pseudomallei and Leptospira portray a very similar spectrum of nonspecific clinical presentations including fever, headache, myalgia, and pneumonia $[4,8]$. In animals, $B$. pseudomallei infections cause pneumonia with lung abscesses, anorexia, and encephalitis [9]. Meanwhile, animal leptospirosis is characterized by abortion, jaundice, and infertility [10]. Several factors, such as bacterial load, underlying medical conditions, and serotypes increase hosts susceptibility to melioidosis and leptospirosis $[1,11-$ 13]. Furthermore, the risk of dual infection is apparent, as several incidences of melioidosis-leptospirosis coinfections were reported previously $[14,15]$. It is possible that many cases may be underdiagnosed when only one between the two tests is considered or available [16].

Early detection of melioidosis and leptospirosis could significantly increase the chances of survival and reduce potential economic loss [17]. Current gold standard for detecting $B$. pseudomallei is by the culture method which requires 2-7 days to grow [18]. Meanwhile, leptospiral antibody titer is detected by the microscopic agglutination test (MAT) that usually requires paired sera and is less useful during acute infection [5]. As both diagnostic methods are time-consuming, a more rapid laboratory assay is urgently needed. To date, several molecular assays have been described for detection of individual B. pseudomallei and Leptospira from the clinical specimens [5, 18]. However, to our knowledge, none of the reported assays is able to simultaneously detect and distinguish B. pseudomallei and Leptospira within the same reaction tube. In this study, we developed a duplex qPCR that can detect B. pseudomallei and Leptospira DNA and evaluated the assay on selected clinical and environmental isolates.

\section{Materials and Methods}

2.1. Microorganism Strains and Growth Conditions. A total of 20 B. pseudomallei strains, 23 Leptospira strains and 39 other microorganisms isolated from human clinical samples and ATCC strains were used in this study (Table 1). These microorganisms were provided by the Department of Medical Microbiology \& Parasitology, School of Medical Sciences, Universiti Sains Malaysia; Makmal Kesihatan Awam Kota Bharu; Universiti Putra Malaysia; and Institute for Medical Research. The bacteria were cultured aerobically in nutrient broth overnight at $37^{\circ} \mathrm{C}$ on a rotating platform of $180 \mathrm{rpm}$. Meanwhile, Leptospira strains were maintained in EMJH media, incubated at $30^{\circ} \mathrm{C}$ on rotating platform of $40 \mathrm{rpm}$, overnight. Entamoeba histolytica DNA was obtained directly from School of Health Sciences, Universiti Sains Malaysia.
2.2. Isolation of Genomic DNA. DNA was extracted from pure bacterial culture using NucleoSpin ${ }^{\circledR}$ Tissue DNA Extraction kit (MACHEREY-NAGEL GmbH \& Co. KG, Germany). The extraction procedure was carried out according to the manufacturer instructions with a minor modification on the final elution step, in which the column was incubated at room temperature for 10 minutes prior to centrifugation at $11000 \times g$. Total DNA was quantified using the Eppendorf BioPhotometer (Eppendorf Scientific, Inc., New York, United States) and stored at $-20^{\circ} \mathrm{C}$ until use.

2.3. Duplex Real-Time PCR Parameters. The PCR reaction was prepared in a total volume of $20 \mu \mathrm{L}$, containing $10 \mu \mathrm{L} 2 \times$

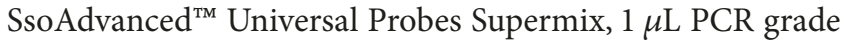
distilled water, $0.2 \mu \mathrm{M}$ primers, $0.1 \mu \mathrm{M}$ probes, and $8 \mu \mathrm{L}$ DNA template. Sequences of oligonucleotides used are listed in Table 2. The oligonucleotides were designed for amplification of the orf 2 region of $B$. pseudomallei type III secretion system (T3SS) and the rrs gene of Leptospira.

Amplifications were conducted using Biorad CFX96 Touch Real-Time PCR Detection System. Thermal cycling condition included an initial denaturation at $95^{\circ} \mathrm{C}$ for 5 minutes, followed by 50 cycles of $95^{\circ} \mathrm{C}$ for 30 seconds and $61.3^{\circ} \mathrm{C}$ for 30 seconds. Baseline threshold for the postamplification analysis was set at 50 (for B. pseudomallei) and 25 (for Leptospira). Any Cq value $\leq 40$ is considered positive. All the amplification in this study was carried out in triplicate, unless specified otherwise.

2.4. Analytical Sensitivity and Specificity. The analytical sensitivity of the assay was carried out using extracted B. pseudomalle $i$ and $L$. interrogans gDNA, diluted 10 -fold ranging from $10 \mathrm{ng} / \mathrm{uL}$ to $1 \mathrm{fg} / \mathrm{uL}$. Two microliters of each diluted gDNA were used in the duplex qPCR. Amount of bacterial DNA in each reaction was calculated based on a formula previously described by Aghamollaei et al. (2015) [21]. Meanwhile, the assay analytical specificity was determined using $2 \mu \mathrm{L}$ extracted DNA from other organisms (non-Leptospira DNAs and non-B. pseudomallei), as listed in Table 1. DNA were extracted using NucleoSpin ${ }^{\circledR}$ Tissue extraction kit.

\section{Results and Discussions}

Despite the availability of several TaqMan hydrolysis probebased assays for the detection of either Leptospira spp. or $B$. pseudomallei, none of the reported assays are able to simultaneously detect both organisms within the same reaction $[18,22]$. Availability of such diagnostic tool that is able to detect and differentiate B. pseudomallei or Leptospira spp. is crucial as both infections portray similar clinical features and yet require different clinical management. In this study, a duplex qPCR for detection of B. pseudomallei and Leptospira spp. DNA was evaluated. As shown in Table 3, the developed qPCR was able to amplify $0.02 \mathrm{pg}$ ( $\sim 4$ copies) Leptospira spp. DNA and $0.2 \mathrm{pg}$ ( 25.6 copies) B. pseudomallei DNA, respectively. The sensitivity of the duplex assay for detection of Leptospira DNA is comparable to other reported leptospiral probe-based assays that detected between 1 and 20 DNA 
TABLE 1: List of organism used for analytical specificity test.

\begin{tabular}{|c|c|c|c|}
\hline Organism & Source & No. tested $(n)$ & Results in duplex qPCR \\
\hline Aspergillus fumigatus & USM, Malaysia & 1 & Negative \\
\hline Bacillus subtilis & USM, Malaysia & 1 & Negative \\
\hline Burkholderia cepacia & USM, Malaysia & 6 & Negative \\
\hline Burkholderia pseudomallei & USM, Malaysia & 20 & Positive \\
\hline Burkholderia thailandensis & USM, Malaysia & 1 & Negative \\
\hline Campylobacter jejuni & USM, Malaysia & 1 & Negative \\
\hline Candida albicans & USM, Malaysia & 1 & Negative \\
\hline Citrobacter freundii & USM, Malaysia & 1 & Negative \\
\hline Entamoeba histolytica & UNAM, Mexico & 1 & Negative \\
\hline Enterococcus faecalis & USM, Malaysia & 1 & Negative \\
\hline Klebsiella pneumoniae & USM, Malaysia & 1 & Negative \\
\hline Leptospira biflexa serovar Patoc & IMR, Malaysia & 1 & Positive \\
\hline Leptospira biflexa serovar Patoc & UPM, Malaysia & 1 & Positive \\
\hline Leptospira borgpetersenii Celledoni & IMR, Malaysia & 1 & Positive \\
\hline Leptospira borgpetersenii serovar Ballum & UPM, Malaysia & 1 & Positive \\
\hline Leptospira fainei serovar Hurtsbridge & IMR, Malaysia & 1 & Positive \\
\hline Leptospira fainei serovar Hurtsbridge & UPM, Malaysia & 1 & Positive \\
\hline Leptospira interrogans serovar Australis & UPM, Malaysia & 1 & Positive \\
\hline Leptospira interrogans serovar Autumnalis & IMR, Malaysia & 1 & Positive \\
\hline Leptospira interrogans serovar Bataviae & IMR, Malaysia & 1 & Positive \\
\hline Leptospira interrogans serovar Bataviae & UPM, Malaysia & 1 & Positive \\
\hline Leptospira interrogans serovar Canicola & UPM, Malaysia & 1 & Positive \\
\hline Leptospira interrogans serovar Copenhageni & IMR, Malaysia & 1 & Positive \\
\hline Leptospira interrogans serovar Hebdomadis & UPM, Malaysia & 1 & Positive \\
\hline Leptospira interrogans serovar Icterohaemorrhagiae RGA & UPM, Malaysia & 1 & Positive \\
\hline Leptospira interrogans serovar Javanica & IMR, Malaysia & 1 & Positive \\
\hline Leptospira interrogans serovar Pomona & IMR, Malaysia & 1 & Positive \\
\hline Leptospira interrogans serovar Pomona & UPM, Malaysia & 1 & Positive \\
\hline Leptospira interrogans serovar Pyrogenes & IMR, Malaysia & 1 & Positive \\
\hline Leptospira interrogans serovar Pyrogenes & UPM, Malaysia & 1 & Positive \\
\hline Leptospira interrogans serovar Tarassovi & IMR, Malaysia & 1 & Positive \\
\hline Leptospira licerasiae serovar Varillal & IMR, Malaysia & 1 & Positive \\
\hline Leptospira meyeri serovar Semaranga & IMR, Malaysia & 1 & Positive \\
\hline Leptospira wolffii & IMR, Malaysia & 1 & Positive \\
\hline Plasmodium falciparum & MKA Kota Bharu & 5 & Negative \\
\hline Plasmodium knowlesi & MKA Kota Bharu & 5 & Negative \\
\hline Plasmodium vivax & MKA Kota Bharu & 5 & Negative \\
\hline Proteus mirabilis & USM, Malaysia & 1 & Negative \\
\hline Proteus vulgaris & USM, Malaysia & 1 & Negative \\
\hline Salmonella Paratyphi A (ATCC 9150) & ATCC, USA & 1 & Negative \\
\hline Salmonella Paratyphi B (ATCC BAA 1250) & ATCC, USA & 1 & Negative \\
\hline Salmonella Paratyphi C (ATCC 9068) & ATCC, USA & 1 & Negative \\
\hline Salmonella Typhi (ATCC 7251) & ATCC, USA & 1 & Negative \\
\hline Salmonella Typhimurium (ATCC 14028) & ATCC, USA & 1 & Negative \\
\hline Staphylococcus aureus & USM, Malaysia & 1 & Negative \\
\hline Staphylococcus saprophyticus & USM, Malaysia & 1 & Negative \\
\hline
\end{tabular}


TABLE 2: List of primers and probes used in this study.

\begin{tabular}{lccc}
\hline Target & Type & Sequence $\left(5^{\prime} \longrightarrow 3^{\prime}\right)$ & Source \\
\hline \multirow{4}{*}{ Leptospira spp. } & Forward primer & ACTGAGACACGGTCCATACT & [19] \\
& Reverse primer & TAGTTAGCYGGTGCTTTAGGYA & \\
\hline \multirow{3}{*}{ Pseudomallei } & Forward primer & FAM-ACGGGAGGCAGC-ZEN-AGTTAAGAATCTTGC-IBFQ \\
& Reverse primer & CCTGGGAGAGCGAGATGTT & [20] \\
& Probe & GCTGGATGAGAAGAAAGTCC & \\
\hline
\end{tabular}

TABLE 3: Analytical sensitivity of the duplex qPCR assays.

\begin{tabular}{|c|c|c|c|c|c|c|c|c|c|}
\hline \multirow{2}{*}{ Copies number } & \multirow{2}{*}{ Amount (pg) } & \multicolumn{3}{|c|}{ Duplex qPCR for B. pseudomallei } & \multirow{2}{*}{ Copies number } & \multirow{2}{*}{ Amount (pg) } & \multicolumn{3}{|c|}{ Duplex qPCR for Leptospira spp. } \\
\hline & & Mean $\mathrm{Cq}$ & SD & $\mathrm{CV}(\%)$ & & & Mean $\mathrm{Cq}$ & SD & $\mathrm{CV}(\%)$ \\
\hline 2560000 & 20000 & 18.41 & 0.05 & 0.26 & 4000000 & 20000 & 19.3 & 0.17 & 0.86 \\
\hline 256000 & 2000 & 21.75 & 0.31 & 1.43 & 400000 & 2000 & 23.09 & 0.16 & 0.67 \\
\hline 25600 & 200 & 25.34 & 0.12 & 0.46 & 40000 & 200 & 27.23 & 0.04 & 0.16 \\
\hline 2560 & 20 & 28.97 & 0.13 & 0.44 & 4000 & 20 & 30.67 & 0.32 & 1.05 \\
\hline 256 & 2 & 32.8 & 0.14 & 0.44 & 400 & 2 & 34.63 & 0.08 & 0.24 \\
\hline 25.6 & 0.2 & 36.96 & 1.06 & 2.88 & 40 & 0.2 & 36.34 & 0.5 & 1.37 \\
\hline 2.56 & 0.02 & - & - & - & 4 & 0.02 & 38.59 & 1.49 & 3.87 \\
\hline 0.256 & 0.002 & - & - & - & 0.4 & 0.002 & - & - & - \\
\hline
\end{tabular}

TABLE 4: PCR efficiency and linearity of the duplex qPCR assays.

\begin{tabular}{lcc}
\hline Parameter & \multicolumn{2}{c}{ Target } \\
& Leptospira spp. & B. pseudomallei \\
\hline Slope & -3.2776 & -3.7006 \\
Efficiency & $101.9 \%$ & $86.3 \%$ \\
Linearity, $\mathrm{R}^{2}$ & 0.9837 & 0.9987 \\
\hline
\end{tabular}

copies per reaction [23-25]. Meanwhile, for the B. pseudomallei detection, the sensitivity was slightly lower than the previously reported assays that amplified 5 and 10 DNA copies per reaction [26-28]. In comparison to the corresponding monoplex assay, the duplex assay had comparable sensitivity for Leptospira, but had a reduced sensitivity for B. pseudomallei target ( $0.2 \mathrm{pg}$ in duplex versus $0.02 \mathrm{pg}$ in monoplex). Reduced performance of multiplex assay as compared to the monoplex assay has been observed in other molecular studies which are associated with primers competition, primer cross hybridization, and template mispriming $[29,30]$. When tested on other microorganisms, no cross amplification was observed (Table 1). The orf2 region is selected because it is only present in B. pseudomallei [31]. Meanwhile, for the leptospiral target, the rrs gene is used because the gene is present in multiple copies per Leptospira genome [32]. As the current panel included limited coverage of organisms, further validation should include Burkholderia mallei and other Burkholderia cepacia complex (BCC).

As listed in Table 4, the duplex assay had an efficiency of $101.9 \%$ for the detection of Leptospira DNA, comparable to the monoplex assay (100.5\%). However, for the detection of $B$. pseudomallei DNA, the duplex assay had an efficiency of $86.3 \%$, lower than the monoplex assay (95.9\%). The suboptimal efficiency may be attributed to the decreased sensitivity of the assay on $B$. pseudomallei target. In an ideal condition, PCR efficiency should be $90 \%$ and above [33]. Further optimization is necessary in order to increase the assay efficiency, especially for the B. pseudomallei target. Meanwhile, in terms of linearity, the duplex assays (for Leptospira and B. pseudomallei DNA detection) had $\mathrm{R}^{2}$ values of close to 1 . Noticeably, at low copy number, the CV values ranged between 2.8 and $3.8 \%$ (Table 3 ).

Overall, the establishment of a duplex qPCR assay that can detect and differentiate B. pseudomallei and Leptospira spp. may help the diagnosis of melioidosis and leptospirosis. However, prior to clinical evaluation, further analytical validation, such as intra- and interassay variation, a wider spectrum of microorganisms for specificity testing, higher number of replicates, and optimization of assays are necessary. In addition, incorporation of internal amplification control should be considered because certain types of clinical samples such as whole blood and urine may cause PCR inhibition.

\section{Data Availability}

The data used to support the findings of this study are available from the corresponding author upon request.

\section{Conflicts of Interest}

The authors declare that there are no conflicts of interest.

\section{Acknowledgments}

We would like to thank laboratory personnel at the Department of Medical Microbiology \& Parasitology, Universiti 
Sains Malaysia; Makmal Kesihatan Awam Kota Bharu; Hospital Raja Perempuan Zainab II, Kota Bharu, for the direct and indirect contribution. The authors would also like to thank the Director General of Health Malaysia for permission to publish this paper. This study was funded by the Research University Grant (1001/PPSP/812144), awarded to the last author. The first author received Yang di-Pertuan Agong Scholarship (BYDPA) by the Public Service Department (JPA) Malaysia.

\section{Supplementary Materials}

The standard curves of the duplex qPCR assays for the detection of B. pseudomallei DNA and Leptospira spp. DNA are illustrated in Figure S1 in Supplementary Material. (Supplementary Materials)

\section{References}

[1] F. Costa, J. E. Hagan, J. Calcagno et al., "Global morbidity and mortality of leptospirosis: a systematic review," PLOS Neglected Tropical Diseases, vol. 9, no. 9, article e0003898, 2015.

[2] D. Limmathurotsakul, N. Golding, D. A. B. Dance et al., "Predicted global distribution of Burkholderia pseudomallei and burden of melioidosis," Nature Microbiology, vol. 1, no. 1, Article ID 15008, 2016.

[3] W. J. Wiersinga, H. S. Virk, A. G. Torres et al., "Melioidosis," Nature Reviews Disease Primers, vol. 4, no. 1, Article ID 17107, 2018.

[4] R. P. Samy, B. G. Stiles, G. Sethi, and L. H. K. Lim, "Melioidosis: clinical impact and public health threat in the tropics," PLOS Neglected Tropical Diseases, vol. 11, no. 5, Article ID e0004738, 2017.

[5] M. Picardeau, "Diagnosis and epidemiology of leptospirosis," Médecine et Maladies Infectieuses, vol. 43, no. 1, pp. 1-9, 2013.

[6] E. A. Kelser, "Melioidosis: a greater threat than previously suspected?" Microbes and Infection, vol. 18, no. 11, pp. 661-668, 2016.

[7] H. Neubauer, L. D. Sprague, M. Joseph et al., "Development and clinical evaluation of a pcr assay targeting the metalloprotease gene (mprA) of B. pseudomallei," Zoonoses and Public Health, vol. 54, no. 1, pp. 44-50, 2007.

[8] D. A. Haake and P. N. Levett, "Leptospirosis in humans," Current Topics in Microbiology and Immunology, vol. 387, pp. 65-97, 2015.

[9] T. Kasantikul, A. Sommanustweechai, K. Polsrila et al., "Retrospective study on fatal melioidosis in captive zoo animals in Thailand," Transboundary and Emerging Diseases, vol. 63, no. 5, pp. e389-e394, 2016.

[10] S. Vidal, K. Kegler, G. Greub et al., "Neglected zoonotic agents in cattle abortion: tackling the difficult to grow bacteria," $B M C$ Veterinary Research, vol. 13, no. 1, p. 373, 2017.

[11] B. Garba, A. R. Bahaman, S. K. Bejo, Z. Zakaria, A. R. Mutalib, and F. Bande, "Major epidemiological factors associated with leptospirosis in Malaysia," Acta Tropica, vol. 178, pp. 242-247, 2018.

[12] K. Suwannarong, P. Singhasivanon, and R. S. Chapman, "Risk factors for severe leptospirosis of Khon Kaen Province: a casecontrol study," Journal of Health Research, vol. 28, no. 1, pp. 5964, 2014.
[13] Y. Suputtamongkol, W. Chaowagul, P. Chetchotisakd et al., "Risk factors for melioidosis and bacteremic melioidosis," Clinical Infectious Diseases, vol. 29, no. 2, pp. 408-413, 1999.

[14] M. R. Mohd Ali, A. W. Mohamad Safiee, P. Thangarajah et al., "Molecular detection of leptospirosis and melioidosis coinfection: a case report," Journal of Infection and Public Health, vol. 10, no. 6, pp. 894-896, 2017.

[15] M. Sapian, M. T. Khairi, S. H. How et al., "Outbreak of melioidosis and leptospirosis co-infection following a rescue operation," Medical Journal of Malaysia, vol. 67, no. 3, pp. 293297, 2012.

[16] A. N. Rafizah, B. Aziah, Y. Azwany et al., "Leptospirosis in Northeastern Malaysia: misdiagnosed or coinfection?" International Journal of Collaborative Research on Internal Medicine \& Public Health, vol. 4, pp. 1419-1427, 2012.

[17] D. Limmathurotsakul and S. J. Peacock, "Melioidosis: a clinical overview," British Medical Bulletin, vol. 99, no. 1, pp. 125-139, 2011.

[18] S. K. Lau, S. Sridhar, C.-C. Ho et al., "Laboratory diagnosis of melioidosis: past, present and future," Experimental Biology and Medicine, vol. 240, no. 6, pp. 742-751, 2015.

[19] M. R. Mohd Ali, A. W. Mohd Safee, N. H. Ismail et al., "Development and validation of pan- Leptospira Taqman qPCR for the detection of Leptospira spp. in clinical specimens," Molecular and Cellular Probes, vol. 38, pp. 1-6, 2018.

[20] M. R. Mohd Ali, P. C. Foo, M. Hassan et al., "Development and validation of TaqMan real-time PCR for the detection of Burkholderia pseudomallei isolates from Malaysia," Tropical Biomedicine, 36, In press.

[21] H. Aghamollaei, M. M. Moghaddam, H. Kooshki, M. Heiat, R. Mirnejad, and N. S. Barzi, "Detection of Pseudomonas aeruginosa by a triplex polymerase chain reaction assay based on lasI/R and gyrB genes," Journal of Infection and Public Health, vol. 8, no. 4, pp. 314-322, 2015.

[22] J. J. Waggoner and B. A. Pinsky, "Molecular diagnostics for human leptospirosis," Current Opinion in Infectious Diseases, vol. 29, no. 5, pp. 440-445, 2016.

[23] R. A. Stoddard, J. E. Gee, P. P. Wilkins, K. McCaustland, and A. R. Hoffmaster, "Detection of pathogenic Leptospira spp. through TaqMan polymerase chain reaction targeting the LipL32 gene," Diagnostic Microbiology and Infectious Disease, vol. 64, no. 3, pp. 247-255, 2009.

[24] S. Villumsen, R. Pedersen, M. B. Borre, P. Ahrens, J. S. Jensen, and K. A. Krogfelt, "Novel TaqMan ${ }^{\circledR}$ PCR for detection of Leptospira species in urine and blood: pit-falls of in silico validation," Journal of Microbiological Methods, vol. 91, no. 1, pp. 184-190, 2012.

[25] I. N. Riediger, R. A. Stoddard, G. S. Ribeiro et al., "Rapid, actionable diagnosis of urban epidemic leptospirosis using a pathogenic Leptospira lipL32-based real-time PCR assay," PLOS Neglected Tropical Diseases, vol. 11, no. 9, Article ID e0005940, 2017.

[26] M. Kaestli, L. J. Richardson, R. E. Colman et al., "Comparison of TaqMan PCR assays for detection of the melioidosis agent Burkholderia pseudomallei in clinical specimens," Journal of Clinical Microbiology, vol. 50, no. 6, pp. 2059-2062, 2012.

[27] R. T. Novak, M. B. Glass, J. E. Gee et al., "Development and evaluation of a real-time PCR assay targeting the type III secretion system of Burkholderia pseudomallei," Journal of Clinical Microbiology, vol. 44, no. 1, pp. 85-90, 2006.

[28] B. Zhang, D. J. Wear, H. Kim, P. Weina, A. Stojadinovic, and M. Izadjoo, "Development of hydrolysis probe-based real-time 
PCR for Identification of virulent gene targets of Burkholderia pseudomallei and B. mallei - a retrospective study on archival cases of service members with melioidosis and glanders," Military Medicine, vol. 177, no. 2, pp. 216-221, 2012.

[29] M. S. Hamilton, M. Otto, A. Nickell, D. Abel, Y. Ballam, and R. Schremmer, "High frequency of competitive inhibition in the Roche Cobas AMPLICOR multiplex PCR for Chlamydia trachomatis and Neisseria gonorrhoeae," Journal of Clinical Microbiology, vol. 40, no. 11, pp. 4393-4393, 2002.

[30] M. N. Nikiforova, W. A. LaFramboise, and Y. E. Nikiforov, "Chapter 4 - amplification-based methods," in Clinical Genomics, pp. 57-67, 2015.

[31] L. Rainbow, C. A. Hart, and C. Winstanley, "Distribution of type III secretion gene clusters in Burkholderia pseudomallei, B. thailandensis and B. mallei," Journal of Medical Microbiology, vol. 51, no. 5, pp. 374-384, 2002.

[32] A. L. T. O. Nascimento, S. Verjovski-Almeida, M. A. van Sluys et al., "Genome features of Leptospira interrogans serovar Copenhageni," Brazilian Journal of Medical and Biological Research, vol. 37, no. 4, pp. 459-478, 2004.

[33] D. Svec, A. Tichopad, V. Novosadova, M. W. Pfaffl, and M. Kubista, "How good is a PCR efficiency estimate: recommendations for precise and robust qPCR efficiency assessments," Biomolecular Detection and Quantification, vol. 3, pp. 9-16, 2015. 


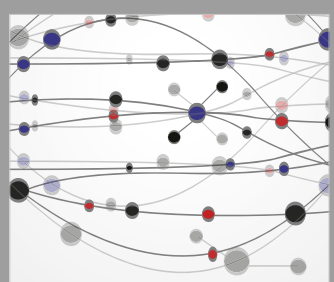

The Scientific World Journal
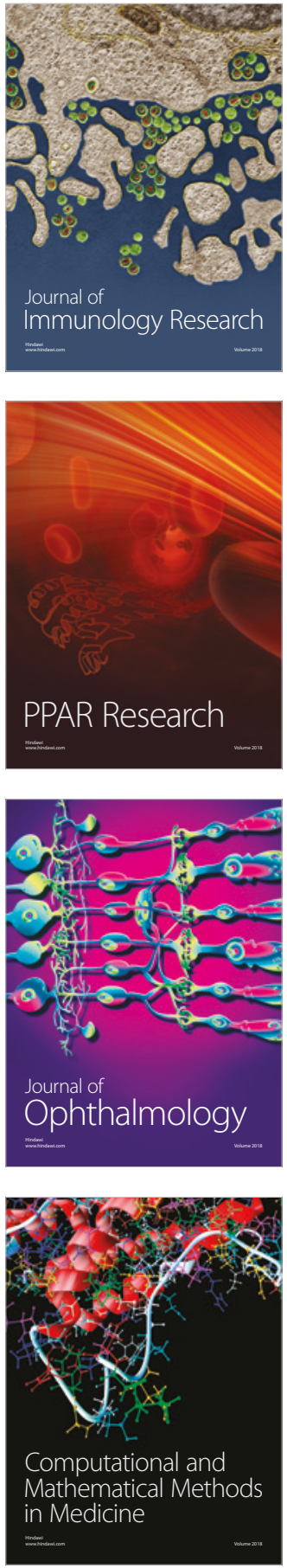

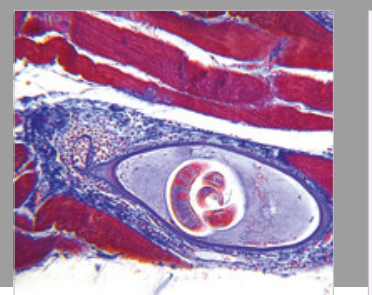

Gastroenterology Research and Practice

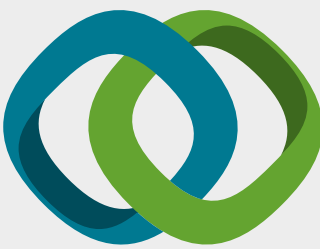

\section{Hindawi}

Submit your manuscripts at

www.hindawi.com
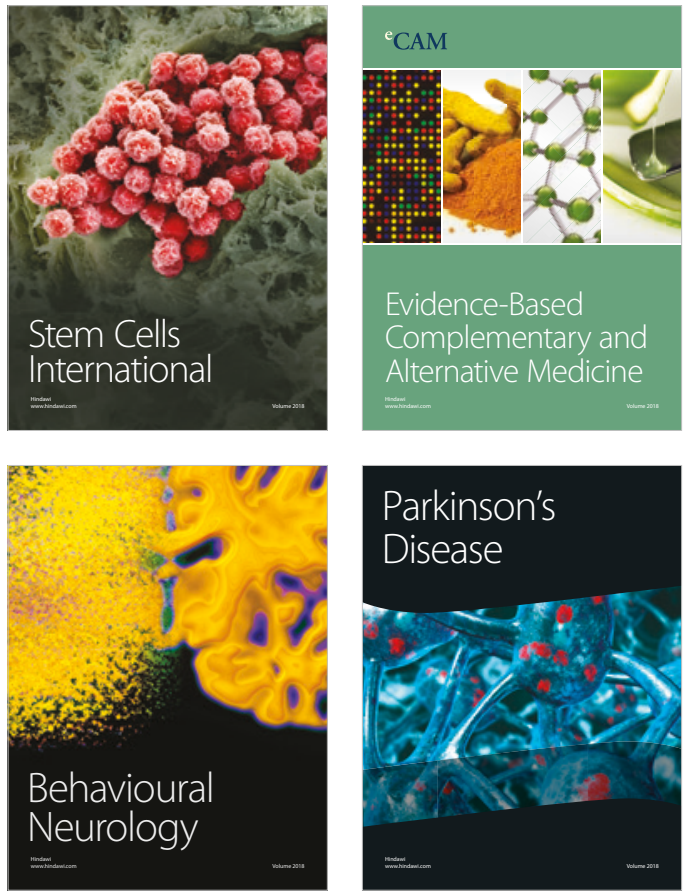

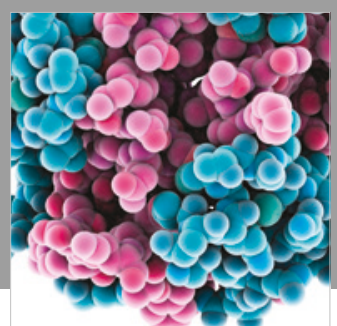

ournal of

Diabetes Research

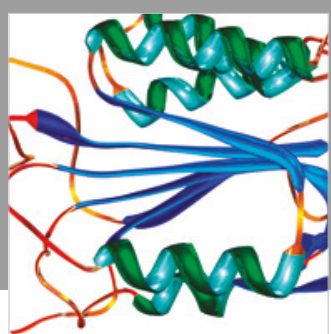

Disease Markers
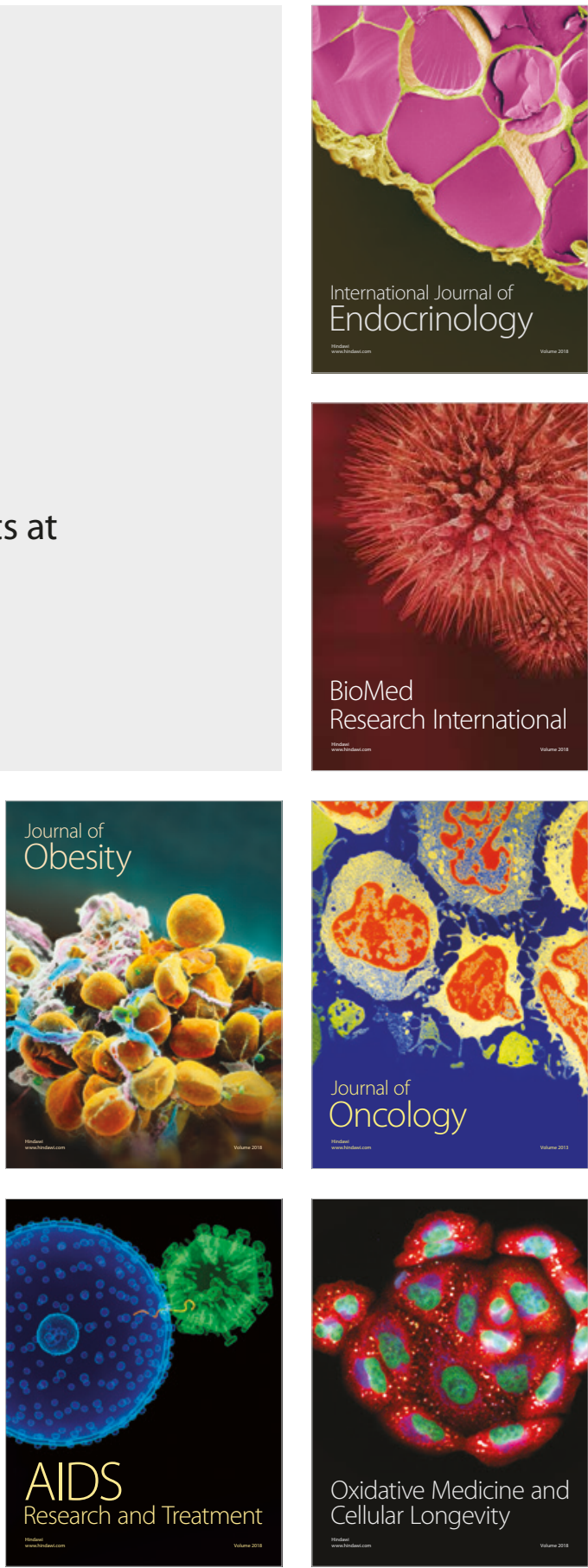